\title{
NUMERICAL ANALYSIS OF INFLUENCE OF DEEP EXCAVATION ON NEARBY EXISTING TUNNEL
}

\author{
B. Viswanath ${ }^{1}$, Krishna. A $^{2}$, Padmashree M. Kallimani ${ }^{3}$ \\ ${ }^{1}$ Assistant professor, Civil Department, UVCE Bangalore University, Karnataka, India \\ ${ }^{2}$ Assistant professor, Civil Department, UVCE Bangalore University, Karnataka, India \\ ${ }^{3}$ former PG student, Civil Department, UVCE Bangalore University, Karnataka, India
}

\begin{abstract}
The constantly increasing urbanization of the metropolises requires more and more realization of a fast and efficient transportation network. Underground transport lines often constitute an ideal solution in term of efficiency and low nuisance for the environment. The technical advancements brought to the underground excavation methods allow the achievement of projects in difficult environmental conditions, especially in urban areas. Providing space for parking, public amenities, etc in multi-storey buildings at town centers has created a need to go deep excavations into ground. The construction of deep excavations in the urban environment is a technically challenging problem. Underground construction may be in the vicinity of already existing tunnels. Deep excavations may have impact on the adjacent tunnels. Such excavation will impose significant influence on the tunnel linings, including changes of stress and deformation. Such effects are observed due to the "space effect" of excavation. The study involves the analysis of influence of deep excavation on the existing tunnel, structural impact on the tunnel lining and measures for controlling the soil and tunnel deformation using finite element software Plaxis (2D). In this study the influence of deep excavation on the existing tunnel with varying position is analyzed. Analysis is carried out by considering tunnel just below the excavation and just beside the excavation. Effect of excavation on tunnel lining and displacement of tunnel due to excavation is observed. Also Analysis involves soil improvement technique to reduce impacts of excavation on tunnel. Grouting method is adopted for the analysis and its role in controlling the effects on tunnel is analyzed.
\end{abstract}

Keywords: Deep excavation, Plaxis 2D, Strut, Displacement, Heave etc... $* * *$

\section{INTRODUCTION}

As urban regions continue to grow both in population and in geographical area, an ever-increasing need arises for additional physical infrastructure. The development of large cities requires the use of the underground area for the construction of transportation infrastructures and facilities. An underground facility like tunnel construction involving deep excavation inevitably causes movements in surrounding soil. The construction of deep excavations in the urban environment is a technically challenging problem. Adjacent construction may be a nuisance to neighboring property owners. Major concern during the planning and execution of deep excavation is the impact of construction related to ground movements on the adjacent properties and utilities. During excavation, the state of stress in the ground mass around the excavation changes. The most common changes in stresses in the retained side are the stress relieve on the excavation face resulting in horizontal ground movement and follows by vertical movement for equilibrium and increase in vertical stress due to lowering of water table resulting in both immediate and consolidation settlement of the ground. This paper presents the study of deep excavation effects on nearby existing tunnels. For the analysis existing tunnel in Bangalore city near K. R Circle and surrounding soil profile for deep excavation is considered and effect of excavation on existing tunnel with varying position is analyzed. Secant piles are used as retaining wall during excavation and struts are used as supporting members to control deformation.

J. J. Chen (2011) performed the numerical study on the movement of existing tunnel due to deep excavation in shanghai and it was observed that as the distance between tunnel and excavation was very small the excavation impact was more [1]. As per the numerical study of deep excavation on existing tunnels done by Xu Huang; Helmut F et, al.(2013) excavation impact depends on parameters like width and depth of excavation. And the impact can be controlled by using suitable measures like grouting.[4]

\section{MATERIALS}

The ground profile comprises of 2 distinct layers; sandy silty soil, highly weathered rock. The soil properties of the model are presented in table 1 
Table 1: Soil parameters

\begin{tabular}{|l|c|c|c|}
\hline \multicolumn{1}{|c|}{ Parameters } & Sandy silt & $\begin{array}{c}\text { Highly } \\
\text { weathered } \\
\text { rock }\end{array}$ & unit \\
\hline $\begin{array}{l}\text { Thickness of } \\
\text { layer }\end{array}$ & 20 & 10 & $\mathrm{~m}$ \\
\hline Dry unit weight & 15.6 & 19 & $\mathrm{kN} / \mathrm{m}^{3}$ \\
\hline $\begin{array}{l}\text { Saturated unit } \\
\text { weight }\end{array}$ & 16.9 & 19 & $\mathrm{kN} / \mathrm{m}^{3}$ \\
\hline $\begin{array}{l}\text { Young's } \\
\text { modulus }\end{array}$ & 50000 & 100000 & $\mathrm{kPa}$ \\
\hline Poission's ratio & 0.3 & 0.3 & - \\
\hline Cohesion & 3 & 0.1 & $\mathrm{kPa}$ \\
\hline $\begin{array}{l}\text { Angle of internal } \\
\text { friction }\end{array}$ & 25 & 30 & $\circ$ \\
\hline Permeability & $8.64 \times 10^{-3}$ & $3.45 \times 10^{-2}$ & $\mathrm{~m} /$ day \\
\hline
\end{tabular}

Table 2: Parameters of secant pile and strut

\begin{tabular}{|l|l|c|l|l|}
\hline Parameter & Symbol & $\begin{array}{l}\text { Secant } \\
\text { pile }\end{array}$ & Strut & Unit \\
\hline $\begin{array}{l}\text { Type of } \\
\text { behavior }\end{array}$ & $\begin{array}{l}\text { Material } \\
\text { type }\end{array}$ & Elastic & Elastic & \\
\hline $\begin{array}{l}\text { Normal } \\
\text { stiffness }\end{array}$ & EA & $1.48 \times 10^{7}$ & $7.56 \times 10^{7}$ & $\mathrm{kN} / \mathrm{m}$ \\
\hline $\begin{array}{l}\text { Flexural } \\
\text { rigidity }\end{array}$ & EI & $7.940 \times 10^{5}$ & $1.91 \times 10^{5}$ & $\mathrm{kNm} / \mathrm{m}$ \\
\hline $\begin{array}{l}\text { Relative } \\
\text { Weight }\end{array}$ & $\mathrm{W}$ & 12.4 & 8.5 & $\mathrm{kN} / \mathrm{m} / \mathrm{m}$ \\
\hline $\begin{array}{l}\text { Poission's } \\
\text { ratio }\end{array}$ & $\mu$ & 0.2 & 0.2 & - \\
\hline $\mathrm{L}_{\text {spacing }}$ & & & 2 & $\mathrm{~m}$ \\
\hline
\end{tabular}

A typical model adopted is as shown in figure 1. Width and depth of excavation adopted is $20 \mathrm{~m}$ and $8 \mathrm{~m}$ respectively. Secant pile of $0.8 \mathrm{~m}$ dia are used as retaining wall and tunnel of $6 \mathrm{~m}$ dia with $0.2 \mathrm{~m}$ thick lining is considered. The actual excavation sequence is modeled as different phases. For the first case existing tunnel at the bottom and exactly at the centre of the above excavation is located and for the second case existing tunnel just adjacent to the excavation is considered as shown in figure 1 and 2 respectively.

Table 3: Properties of tunnel lining

\begin{tabular}{|l|l|c|l|}
\hline Parameter & Symbol & Tunnel lining & Unit \\
\hline Type of behavior & $\begin{array}{l}\text { Material } \\
\text { type }\end{array}$ & Elastic & - \\
\hline Normal stiffness & EA & $9.898 \times 10^{6}$ & $\mathrm{kN} / \mathrm{m}$ \\
\hline Flexural rigidity & EI & $6.470 \times 10^{4}$ & $\mathrm{kNm} / \mathrm{m}$ \\
\hline
\end{tabular}

\begin{tabular}{|l|c|c|c|}
\hline Relative Weight & $\mathrm{W}$ & 4.34 & $\mathrm{kN} / \mathrm{m} / \mathrm{m}$ \\
\hline Poission's ratio & $\mu$ & 0.2 & - \\
\hline
\end{tabular}

During the analysis for both the cases the distance between bottom of excavation and tunnel axis is varied as $1 \mathrm{D}, 1.5 \mathrm{D}$ and $2 \mathrm{D}$, where $\mathrm{D}$ is the diameter of the tunnel. The models are represented as $T_{1}, T_{2}$ and $T_{3}$ for first case . similarly $T_{4}, T_{5}$ and $\mathrm{T}_{6}$ for second case.

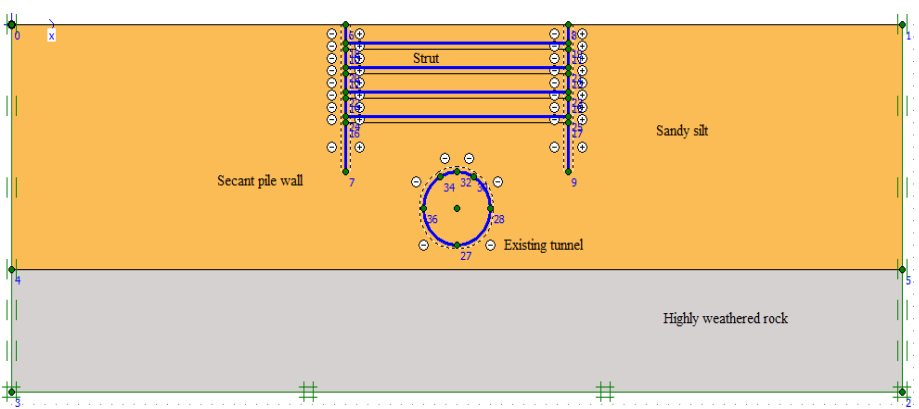

Fig -1 Geometric model $\left(\mathrm{T}_{1}\right)$

Excavation Scheme: Excavation is done into 10 phases as listed below

1. Activation of retaining wall and existing tunnel.

2. General excavation till $2 \mathrm{~m}$ from ground level.

3. Activation of first level of strut at $1.5 \mathrm{~m}$ from ground level.

4. General excavation till $4 \mathrm{~m}$ from ground level.

5. Activation of second level of strut at $3.5 \mathrm{~m}$ from ground level.

6. Excavation till $6 \mathrm{~m}$ depth from ground level.

7. Activation of third level of strut at $5.5 \mathrm{~m}$ from ground level.

8. Lower the water table to $8 \mathrm{~m}$

9. Excavation to a next depth $8 \mathrm{~m}$ from ground level.

10. Activation of level fourth level strut at $7.5 \mathrm{~m}$ from ground level.

Figure 2 represents the model for second case with tunnel located just beside to the excavation and excavation is carried out into phases as mentioned above for first case.

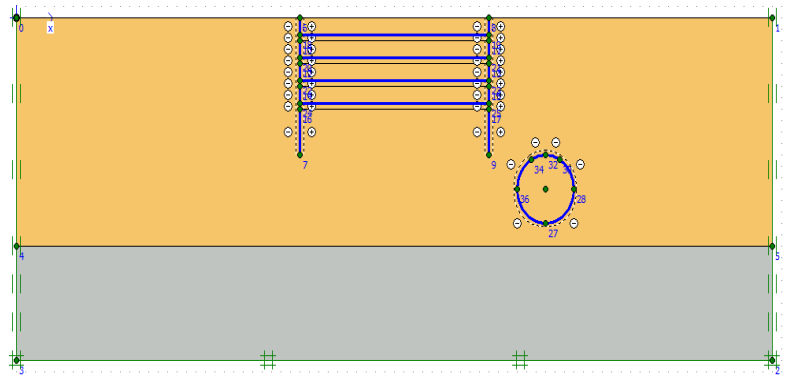

Fig -2: Geometric model $\left(\mathrm{T}_{4}\right)$ 


\section{RESULTS AND DISCUSSION}

The effect of excavation on the existing tunnel are presented in the heave of tunnel in longitudinal direction and phase wise is shown in graphs for both the cases.

\subsection{Excavation with Tunnel Located at the Bottom of}

\section{Excavation}

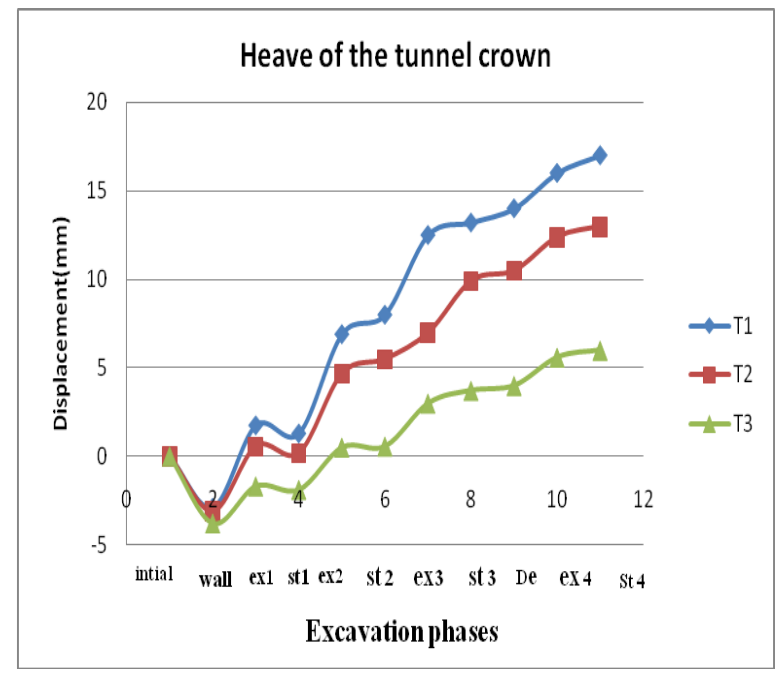

Fig- 3: Heave of the tunnel crown

In the above graph wall represents the construction of retaining wall, ex 1 means soil excavation of the first layer, De refers to dewatering of the soil layer. Width of excavation is $20 \mathrm{~m}$. For the tunnel is directly beneath the excavation largest displacement of the tunnel lining occurs at the crown. The displacement rates increases in the final excavation stages. As the distance between the excavation and the tunnel increases, the heave of tunnel crown reduces. The maximum heave of about $18 \mathrm{~mm}$ is obtained for the excavation being closest to the tunnel which is reduced to about $6 \mathrm{~mm}$ for the excavation being $2 \mathrm{D}$ from the tunnel axis. It is found that excavations over the tunnels have a negative effect on tunnel lining. This is due to the reduction of the normal forces and increase in the bending moments as a result of unloading due to the excavation.

Figure 4 shows the longitudinal tunnel deflection for scenarios $\mathrm{T}_{1}-\mathrm{T}_{3}$. Tunnel heave is significant in the middle section. It can be observed that the influence of the excavation stretches sideward from the end of the excavation approximately 0.5 times the width of the excavation. Due to the above excavation tunnel undergoes displacement which comprises the displacement of tunnel crown and tunnel invert. The main response of tunnel structure due to above ground excavation is longitudinal heave, which is about twice the convergence of the tunnel cross section.

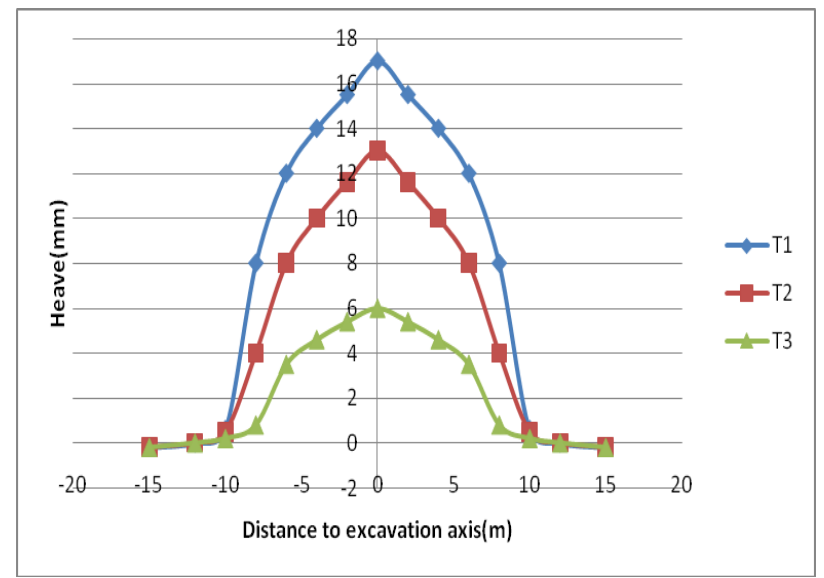

Fig- 4: Tunnel deflection in longitudinal direction

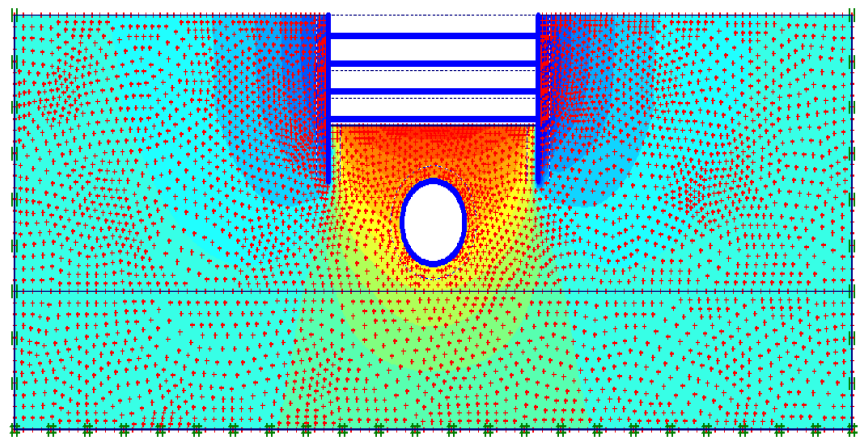

Fig-5: Ground movement

The above figure presents the contours of vertical soil displacements for $\mathrm{T}_{1}$. The settlements are observed near the retaining wall at the surface, while the soil below the excavation bottom moves upward. The width of the settlement trough at one side of the longitudinal wall for scenarios $T_{1}, T_{2}$ and $\mathrm{T}_{3}$ is approximately 16,18 and $18 \mathrm{~m}$ respectively. The maximum soil heave below the excavation bottom is $36 \mathrm{~mm}$ for $\mathrm{T}_{1}$ and about $28 \mathrm{~mm}, 25 \mathrm{~mm}$ for scenarios $\mathrm{T}_{2}$ and $\mathrm{T}_{3}$ respectively. when the distance between excavation bottom and tunnel axis is larger than $1.5 \mathrm{D}$, the influence of the tunnel structure on the soil movement is negligible.

The effect of excavation tunnel lining due to nearby excavations is as represented in figure 6 . The change in bending moment before and after excavation is observed and also the bar chart of bending moment results that as distance between tunnel and excavation increases the bending moment of tunnel crown and invert decreases. 

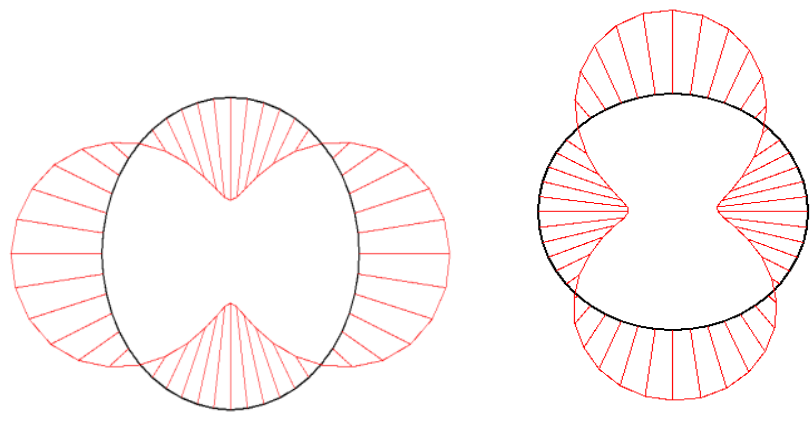

(a) Before excavation

b) After excavation

Fig -6: Effect of excavation on tunnel lining before and after excavation for first case

\subsection{Excavation just beside to the Existing Tunnel}

The analysis involves study of influence of excavation on the tunnel for a condition where the excavation is situated in a horizontal distance to the existing tunnel. The excavation impact on the existing tunnel located at a distance adjacent to excavation is not highly significant compared to that of the excavation over the centrally located bottom tunnel, because the retaining wall for the excavation provides a shield for the tunnel.

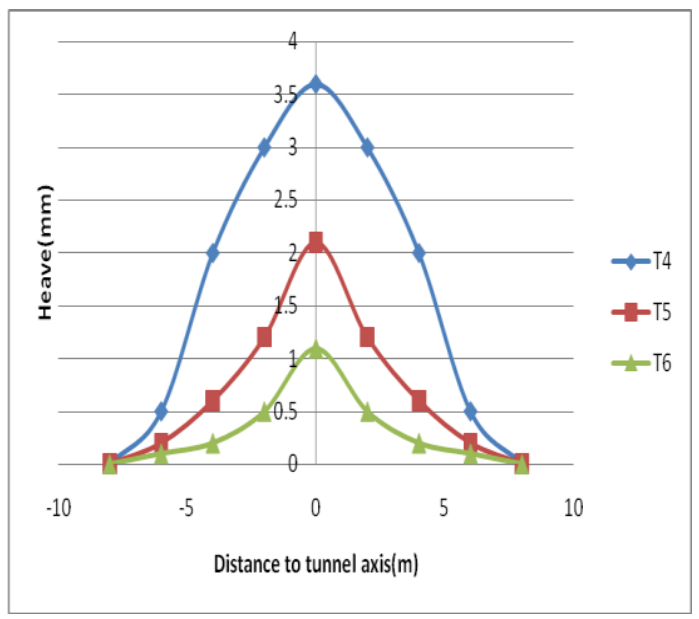

Fig -7: Longitudinal deflection of tunnel

For scenarios $T_{4}, T_{5}$ and $T_{6}$, centre of the excavation is situated in a horizontal distance to the tunnel axis of $1,1.5$ and 2 times the tunnel diameter, the vertical displacements are negligible in this case and the changes in the structural forces are also minor because the retaining wall for the excavation provides a "shield" for the tunnel. Figure 7 presents the tunnel deflection in longitudinal direction. For scenarios $T_{4}, T_{5}$ and $\mathrm{T}_{6}$, the depth of the tunnel is the same and as the horizontal distance between tunnel and excavation increase, the displacement of tunnel lining decreases.

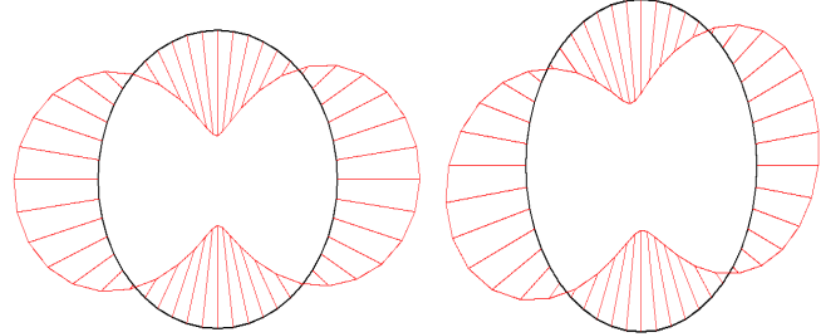

Fig -8: Effect of excavation on tunnel lining before and after excavation for second case

\section{EFFECT OF SOIL IMPROVEMENT}

Ground improvement technique is the process of improving the geo-technical characteristics of soil used in construction. Grouting is a widely used method for strengthening by increasing the stiffness. By increasing the stiffness of a soil, rebound effect on tunnel due to excavation, structural impact on tunnel lining and displacements can be reduced

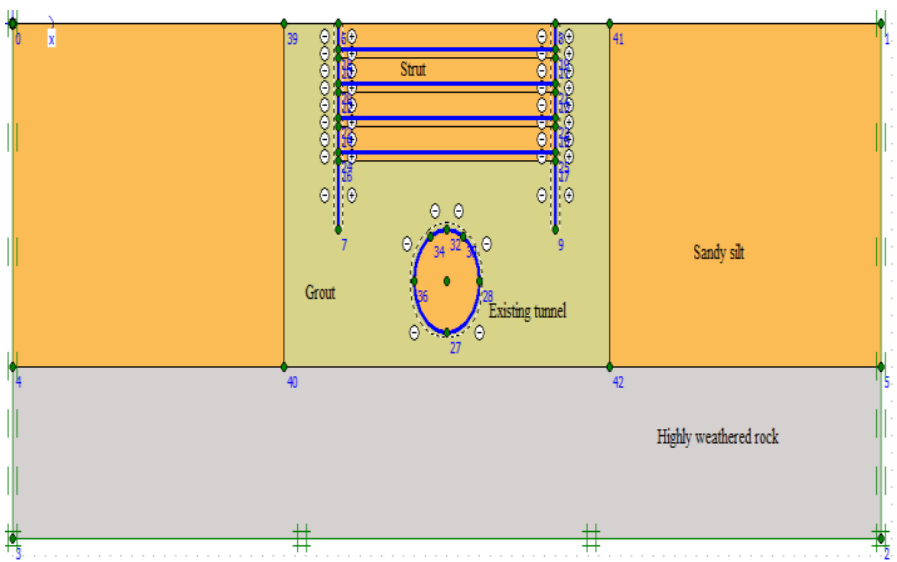

Fig -9: Cross section of the improved soil

To investigate the effect of soil improvement, the stiffness is increased twice and analysis is carried out for the scenario $T_{1}$. The width of soil improvement is $20 \mathrm{~m}$, just at the bottom of excavation surrounding the tunnel and extends to $5 \mathrm{~m}$ outside the excavation in both lateral direction. The parameters of the improved soil are as given in table 4

Table 4: Properties of improved soil

\begin{tabular}{|c|c|c|}
\hline Parameters & Sandy silt & Unit \\
\hline Young's modulus & 100000 & $\mathrm{kPa}$ \\
\hline Cohesion & 10 & $\mathrm{kPa}$ \\
\hline $\begin{array}{c}\text { Angle of internal } \\
\text { friction }\end{array}$ & 30 & $\circ$ \\
\hline
\end{tabular}



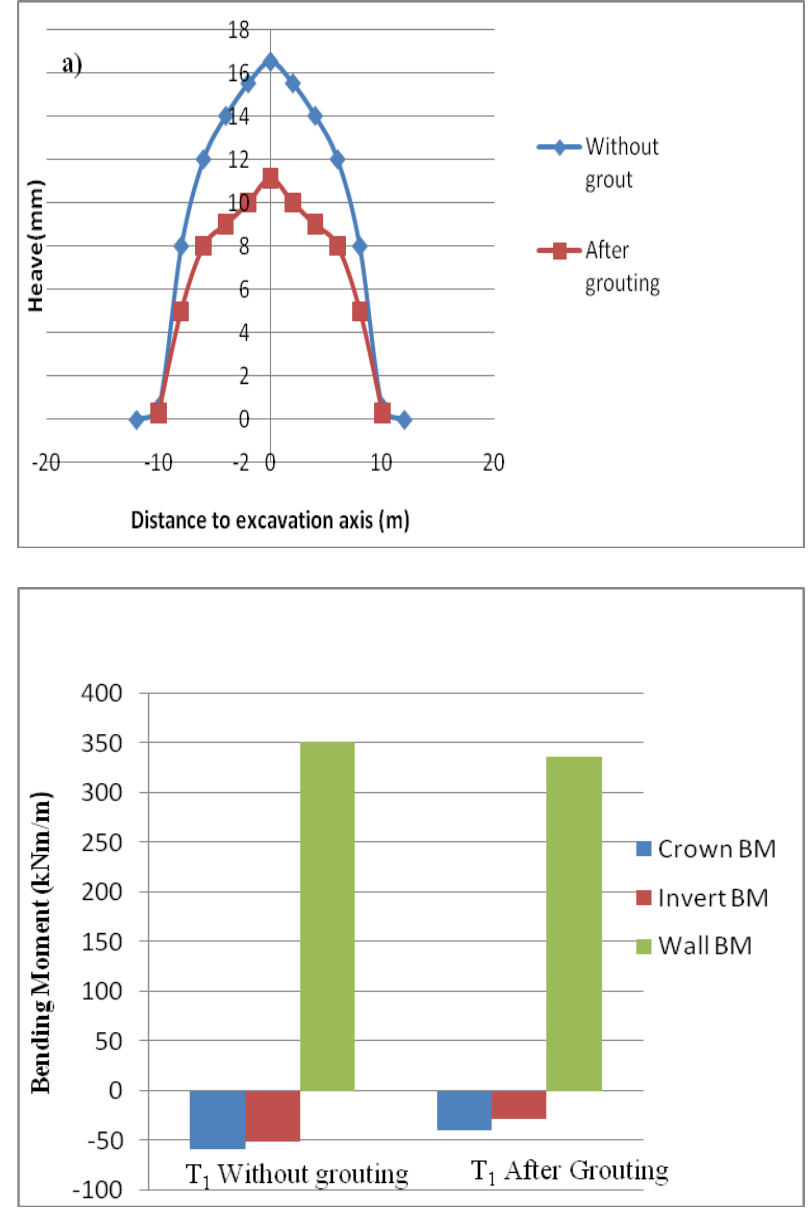

Fig -10: Effect of grouting a) Tunnel deflection b) Bending moment

Results of analysis showed that soil improvement reduces the heave of the tunnel crown in the order of $33 \%$. The bending moment of crown, invert and wall is reduced to about $33 \%$, $43 \%$ and $4.2 \%$ respectively by increasing the soil stiffness.

\section{CONCLUSIONS}

1. Deep excavations near the existing tunnel have significant influence on structural stability of tunnel lining.

2. Significant heave of the tunnel occurs when the tunnel is underlying the excavation and the influence stretches sideward from the end of the excavation.

3. When the distance between the bottom of excavation and the tunnel axis is larger than the $1.5 \mathrm{D}$, the influence of tunnel structure on the soil movement is negligible.

4. When the tunnel is situated at the side of the excavation, the influence on the tunnel is not significant, as the retaining walls constructed to the level of the tunnel provide a shielding effect.
5. Soil improvement technique can be adopted to reduce the influence on the tunnel due to deep excavation activities.

6. By cement grouting, both tunnel displacement and bending moment can be reduced to about $30 \%$.

\section{REFERENCES}

[1]. Chen J.J , Wen S.K (2011), "Numerical Study on the Movement of Existing Tunnel Due to Deep Excavation in Shanghai" Geotechnical Engineering Journal of the SEAGS \& AGSSEA Vol. 42 No.3 September 2011 ISSN 0046-5828

[2]. Dilip kumar S.K, "Numerical analysis of Deformations induced by urban tunneling", M.E Thesis, Bangalore university (2011)

[3]. Jun-Feng Zhang and Yan-Fei Zhu, (2013) "Prediction of tunnel displacement induced by adjacent excavation in soft soil", Tunnelling and Underground Space Technology 36, 2013, pp. 24-33.

[4]. Xu Huang, Helmut F. Schweiger and Hongwei Huang "Influence of Deep Excavations on Nearby Existing Tunnels", (2013) international journal of geomechanics (c) asce / march/april, 2013, pp. 170-180.

[5]. 18. Zheng Gang and Wei Shao-wei (2008) "Numerical analyses of influence of overlying pit excavation on existing tunnels", J. Cent South Univ. Technol. 2008, 15(s2), pp. 69-75 